
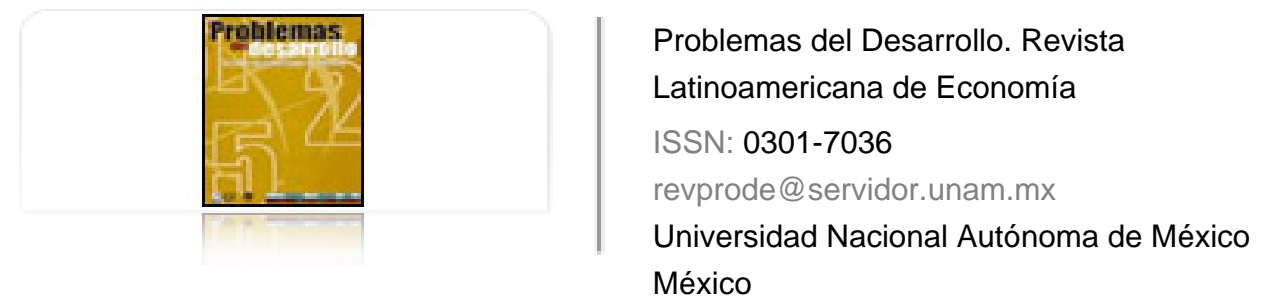

Azpiazu, Daniel; Schorr, Martín

LA INDUSTRIA ARGENTINA EN LA POSCONVERTIBILIDAD: REACTIVACIÓN Y LEGADOS DEL

NEOLIBERALISMO

Problemas del Desarrollo. Revista Latinoamericana de Economía, vol. 41, núm. 161, abril-junio, 2010, pp. 111-139

Universidad Nacional Autónoma de México

Distrito Federal, México

Disponible en: http://www.redalyc.org/articulo.oa?id=11820105005

- Cómo citar el artículo

- Número completo

- Más información del artículo

Página de la revista en redalyc.org

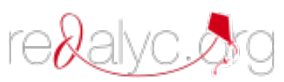

Sistema de Información Científica

Red de Revistas Científicas de América Latina, el Caribe, España y Portugal Proyecto académico sin fines de lucro, desarrollado bajo la iniciativa de acceso abierto 


\title{
LA INDUSTRIA ARGENTINA EN LA POSCONVERTIBILIDAD: REACTIVACIÓN Y LEGADOS DEL NEOLIBERALISMO
}

\author{
Daniel Azpiazu y Martín Schorr*
}

A la memoria de Hugo J. Nochteff

Fecha de recepción: 22 de octubre de 2009. Fecha de aceptación: 12 de febrero de 2010.

\section{Resumen}

El artículo explora las principales características de la evolución de la industria manufacturera de la Argentina en la posconvertibilidad, es decir, en la etapa iniciada a partir de 2002. Entre las dimensiones analíticas que se tratan, destacan: a) los sesgos estructurales de la importante recuperación fabril de los años recientes; b) el comportamiento laboral, las formas asumidas por la distribución funcional del ingreso en el sector y la apropiación de ganancias extraordinarias por parte de los principales oligopolios de la actividad; c) las modalidades de inserción del sector manufacturero en el mercado mundial; $y$, a modo de balance, d) la identificación de las principales líneas de continuidad y ruptura entre la posconvertibilidad y el "modelo de los noventa".

Palabras clave: industria manufacturera, modelo de acumulación, mercado de trabajo, distribución del ingreso, grandes empresas, intercambio comercial, poder económico.

* Investigadores del Consejo Nacional de Investigaciones Científicas y Técnicas (Conicet) y del Área de Economía y Tecnología de la Facultad Latinoamericana de Ciencias Sociales (Flacso), Argentina. Este artículo se terminó de redactar a comienzos de noviembre de 2009 y se realizó en el marco del Proyecto PIP 03153: Desempeño y transformaciones de la cúpula empresaria argentina y la cúpula industrial entre 1991 y 2008. Rupturas y continuidades entre la convertibilidad y la posconvertibilidad, con patrocinio del Conicet. Se agradecen las aportaciones de los tres jurados anónimos que evaluaron el artículo, a quienes se exime de cualquier responsabilidad en cuanto a los errores $\mathrm{u}$ omisiones que pudieran existir. 


\section{Abstract}

The article explores the principal characteristics of the evolution of manufacturing industry in Argentina's post-convertibility period, that is, during the period starting in 2002. Among the analytical dimensions dealt with, the following stand out: a) structural biases in the important manufacturing recovery of recent years; b) labor performan$c e$, the forms assumed by functional income distribution in the sector and the appropriation of extraordinary gains by the leading manufacturing oligopolies; c) modes of insertion by the manufacturing sector in the world market; and, to balance this, d) an identification of the main lines of continuity and rupture between the post-convertibility period and the "1990s model".

Keywords: manufacturing industry, accumulation model, labor market, income distribution, large companies, commercial exchange, economic power.

\section{Résumé}

Cet article explore les principales caractéristiques de l'évolution de l'industrie manufacturière de l'Argentine à l'ère de la Post-convertibilité, c'est-à-dire au cours de cette étape qui a débuté en 2002. Parmi les dimensions traitées dans l'analyse, se distinguent: a) les biais structuraux de l'importante récupération du secteur manufacturier de ces dernières années; b) le comportement du travail, les formes assumées par la distribution fonctionnelle du revenu dans le secteur manufacturier et l'appropriation de bénéfices extraordinaires de la part des principales oligopoles de l'activité; c) les modalités de l'insertion du secteur manufacturier sur le marché mondial; et en guise de bilan, d) l'identification des principales lignes de continuité et de rupture entre la Post-convertibilité et le "modèle des années 90".

Mots clés: industrie manufacturière, modèle d'accumulation, marché du travail, distribution du revenu, grandes entreprises, échange commercial, pouvoir économique.

\section{Resumo}

O artigo explora as principais características da evolução da indústria manufatureira da Argentina na Pós-convertibilidade, ou seja, na etapa iniciada a partir de 2002. Entre as dimensões analíticas tratadas, destacam-se: a) os vieses estruturais da importante recuperação fabril dos anos recentes; b) o comportamento laboral, as formas assumidas pela distribuição funcional do ingresso no setor e a apropiação de ganhos extraordinários por parte dos principais oligopólios da atividade; c) as modalidades de inserção do setor manufatureiro no mercado mundial; e a título de balanço, d) a identificação das principais linhas de continuidade e ruptura entre a Pós-convertibilidade e o"modelo dos anos noventa".

Palavras-chave: indústria manufatureira, modelo de acumulação, mercado de trabalho, distribuição de ingresso, grandes empresas, intercâmbio comercial, poder econômico. 


\section{Introducción}

espués de más de un cuarto de siglo de sostenido deterioro relativo en los esD cenarios latinoamericano e internacional, la economía e industria argentinas revelaron tasas de expansión extraordinarias durante el periodo 2002-2008. Tomando como referencia la información compatibilizada por la CEPAL ${ }^{1}$, en Argentina los ritmos de crecimiento anual acumulativo ( $8.5 \%$ y $9.4 \%$, respectivamente) duplicaron holgadamente a los registrados en los principales países de la región (Brasil: $4.1 \%$ y $3.6 \%$; y México: $3.0 \%$ y $2.2 \%$, respectivamente), así como a los de América Latina en su conjunto ( $4.8 \%$ y $4.2 \%$, respectivamente). Se trata de una peculiar imagen de espejo invertido respecto de los comportamientos del periodo 1997-2002, en el que la economía e industria latinoamericanas, entre ellas las de Brasil y México, revelaron tasas positivas de crecimiento, mientras que en Argentina el PIB total cayó a una tasa media anual de $3.2 \%$, al tiempo que el correspondiente al sector fabril lo hizo en un $5.7 \%$ por año.

Tan disonantes desempeños han tenido a la economía e industria argentinas como su factor explicativo por excelencia, y al año 2002 como un punto de ruptura en numerosos aspectos. En efecto, con sus matices y especificidades, las economías e industrias latinoamericanas revelaron ciertos sesgos que, a la vez, no estuvieron disociados del escenario internacional en el que se insertan. Sin embargo, en el atípico ejemplo argentino, los factores generales parecerían casi subalternos frente a componentes endógenos que, en tan contrastantes fases del ciclo, asumieron una intensidad muy distante de la que adoptaron en las restantes economías e industrias de la región.

Mientras a finales de siglo (particularmente desde mediados de 1998) el caso argentino ingresó en la fase terminal de un esquema de ajuste estructural y hegemonía de la valorización financiera cuya génesis histórica se sitúa en ese gran quiebre histórico que fue la dictadura militar de 1976-1983² a comienzos del siglo XXI, implosión del régimen de convertibilidad mediante, se inició una intensa fase de reactivación económica y fabril que invita a la reflexión.

La devaluación monetaria implementada a principios de 2002 trajo aparejado un profundo reordenamiento de los precios relativos de la economía (incluyendo sobre todo el tipo de cambio y los salarios), una severa crisis económica (caída superior al $10 \%$ en el PIB total y en el industrial) y, en suma, el punto de quiebre del modelo

Disponible en http://websie.eclac.cl/sisgen (consultado el 20 de octubre de 2009).

2 En Basualdo (2006) se presenta una caracterización del régimen de valorización financiera, su larga hegemonía en la economía doméstica y su derrumbe a principios de 2002. 
hegemónico. A partir de ese por demás crítico año 2002, la economía argentina y su sector manufacturero iniciaron una senda sostenida de expansión, con altas tasas de crecimiento que llevan a plantearse algunos interrogantes: ¿se trata de un simple "efecto rebote" dada la magnitud de la crisis económica precedente?, ¿se está en presencia de la conformación de un nuevo modelo de acumulación o, por el contrario, se trata de una fase de reactivación económica y fabril sin cambios estructurales?, ¿es un proceso acelerado de reindustrialización que impulsa al conjunto de la economía?, ¿se está ante un cambio de régimen económico con potencialidades de inscribirse en un sendero virtuoso de desarrollo nacional?

En ese marco se inscriben las presentes reflexiones, que intentan aportar algunos elementos de juicio tendientes a caracterizar el proceso de crecimiento verificado en la posconvertibilidad, muy particularmente en lo que se vincula al papel que en el mismo asumió la industria manufacturera, los rasgos que subyacen en la pronunciada recuperación fabril y sus connotaciones en la búsqueda de un patrón evolutivo que la pueda tener como pilar del desarrollo.

Con estos objetivos, en la próxima sección se analizan las principales características de la expansión económica de los últimos años, centrándose en el desempeño de las actividades industriales, sus distintas dinámicas, el perfil productivo sectorial y, desde esas perspectivas, la identificación de continuidades y rupturas con el "modelo de los noventa" y, más ampliamente, el largo proceso de desindustrialización y de reestructuración regresiva del sector iniciado en la segunda mitad de la década de 1970. Con base en esas referencias, en la tercera sección se estudian los consiguientes impactos sobre el mercado de trabajo industrial, la generación de empleos, la distribución funcional del ingreso y el desempeño económico de las grandes empresas en la posconvertibilidad. El objetivo principal de la cuarta sección es desentrañar algunas problemáticas vinculadas a la dinámica reciente del comercio exterior de manufacturas, su perfil estructural y las restricciones que surgen de la inexistencia de una política industrial que se inserte en un proyecto de desarrollo inclusivo de mediano y largo plazos. Este último tema se retoma en las reflexiones finales.

\section{Recuperación económica, dinámica y perfil manufacturero}

\section{en la posconvertibilidad}

Aunque parezca sorprendente, fue necesario que transcurrieran más de tres décadas para que la economía argentina y su sector industrial crecieran durante más de cinco años consecutivos. Efectivamente, hay que remontarse a mediados del decenio de 1960 para que, en el marco de la estrategia de sustitución de importaciones, se 
pueda encontrar un periodo de tal naturaleza ${ }^{3}$. La abrupta interrupción del modelo sustitutivo a causa de las políticas seguidas por la dictadura militar de 1976 ocasionó una prolongada etapa de desindustrialización, reestructuración regresiva de un cada vez más reducido y resquebrajado espectro fabril; proceso que tuvo como correlato la creciente hegemonía de la valorización financiera y un ajuste estructural profundamente retrógrado. La reconquista de la democracia en 1983 no produjo cambios importantes; todo lo contrario, hacia finales de los ochenta se inició una nueva fase en la que las políticas públicas neoliberales profundizaron y avanzaron sobre ciertas asignaturas pendientes del gobierno dictatorial y afianzaron en grados extremos el señalado cuadro industrial.

En consecuencia, entre 1991 y 2001 (último año de vigencia plena de la convertibilidad) el sector industrial creció apenas un 10\% (una tasa media anual inferior a 1\%), al tiempo que su participación en el producto agregado se contrajo casi tres puntos porcentuales (de $18.1 \%$ a $15.4 \%$, respectivamente). Al magro desempeño fabril se aunó la desintegración del entramado sectorial, la expulsión de mano de obra y la redistribución regresiva del ingreso, un perfil crecientemente volcado hacia la explotación de ventajas comparativas naturales y $\mathrm{Al}$ aprovechamiento de nichos privilegiados por las políticas públicas (como la industria automotriz y otras actividades de ensambladura o de enclave), y crecientes niveles de concentración productiva y centralización del capital inscritos en una aceleradísima extranjerización ${ }^{4}$.

La crisis estructural del modelo de los noventa comenzó a manifestarse de modo incipiente a mediados de 1998 y, a partir de entonces, ingresó en su fase terminal e irresoluble en el marco de las políticas y estrategias que lo sustentaban. Así, entre 1997 y 2001, el PIB global cayó 4.8\%, al tiempo que el industrial lo hizo en un 16.5\% (porcentajes que involucrando al año 2002 alcanzan valores extremos y difíciles de interpretar en una economía que no sufrió ningún cataclismo natural ni un conflicto bélico de gran envergadura: $15.2 \%$ y $25.6 \%$, respectivamente). Sin duda, tal desempeño fue uno de los resultados previsibles del despliegue de políticas que, en su momento, convertían a la Argentina en uno de los mejores y más disciplinados alumnos

3 En realidad lo superó holgadamente en lo temporal, en tanto el crecimiento sostenido e ininterrumpido se extendió a 11 años (1964-1974) a un ritmo medio de 5.1\% anual acumulativo; tasa que se elevó a 7\% anual en el sector manufacturero.

4 La dinámica manufacturera durante la convertibilidad ha sido estudiada, entre otros, por Azpiazu (1994) y Kosacoff (1998). Asimismo, una visión del proceso industrial de la década de 1990 en perspectiva histórica se puede encontrar en Azpiazu y Schorr (en prensa), Katz (1999) y Kosacoff (2000). 
del neoliberalismo extremo, de las "recomendaciones" de los organismos multilaterales de crédito y sus adláteres locales (think tanks que en muchos casos tuvieron una participación activa en la formulación y la implementación de las mismas) ${ }^{5}$.

Como era de esperar, la salida de los rígidos corsés impuestos por la convertibilidad resultó por demás traumática, y produjo turbulencias significativas en materia de precios relativos. Así, por ejemplo, al cabo de ese crítico año 2002, el tipo de cambio con el dólar estadounidense había acumulado un incremento de $249.1 \%$ (con un pico de 265\% a mediados de año), los precios minoristas habían registrado un alza de $40.9 \%$, porcentaje que se elevaba a 118 en el caso de los precios mayoristas, y se reducía a apenas 13.3 en lo relativo a los salarios medios en la industria.

A partir de ese profundo y generalizado reacomodamiento de los precios relativos domésticos y los que vinculan la economía argentina al exterior, aparecieron nuevos escenarios macro y mesoeconómicos, que derivaron en el paulatino desplazamiento de la valorización financiera y el ajuste estructural regresivo como esquema hegemónico durante largos años.

Al respecto, la gráfica 1 permite comprobar que entre 2002 y 2008 la economía argentina y su sector manufacturero revelaron una expansión notable: $63.3 \%$ y $71.6 \%$, respectivamente. En función de esos disímiles ritmos de crecimiento, parecería haberse revertido (al menos considerando los años extremos de la serie) el prolongado proceso de desindustrialización iniciado con la última dictadura militar.

En ese sentido, muy particularmente en lo relativo al desempeño fabril y su intrínseca potencialidad propulsora del crecimiento agregado de la economía, podría reconocerse un primer "efecto rebote" centrado en la gravitación decisiva de las exportaciones industriales. Ello, merced a la convergencia de un nuevo (mucho más elevado) tipo de cambio real, la más que considerable reducción de los salarios locales en dólares y la existencia de elevados niveles de capacidad ociosa (precisamente en actividades que contaban con amplias posibilidades de inserción en mercados internacionales caracterizados por precios y demandas en alza). Así, entre 2001 y 2005, mientras las exportaciones de manufacturas se incrementaron $60.8 \%$, el valor bruto de la producción sectorial medido en dólares corrientes sólo aumentó $13.1 \%$. En ese escenario, la atención de la demanda externa dio cuenta de $85.7 \%$ del crecimiento fabril durante el quinquenio aludido. Como se analiza más adelante, se trató mayoritariamente de agroindustrias,

5 El 6 de enero de 2002, poco tiempo después de la declaración unilateral de cesación de pagos de la deuda externa y la sucesión de cinco mandatarios presidenciales en menos de dos semanas, con la sanción de la Ley 25561 de "emergencia pública y reforma del régimen cambiario" se formalizó la demorada salida del régimen de convertibilidad. 
commodities y algunas actividades de ensambladura, en las que, en muchos casos, su condición de industrias de procesos de naturaleza capital-intensiv0 y muy volcadas hacia el procesamiento de recursos básicos les confirió la posibilidad cierta de pasar a constituirse en sólidas plataformas de exportación (trascendiendo, en muchos casos con creces, el tradicional comportamiento contracíclico de sus colocaciones externas).

\section{Gráfica 1}

Argentina. Evolución del PIB total e industrial y participación de la industria en el PIB total, 1997-2008 (en índices $1997=100$ y porcentajes)

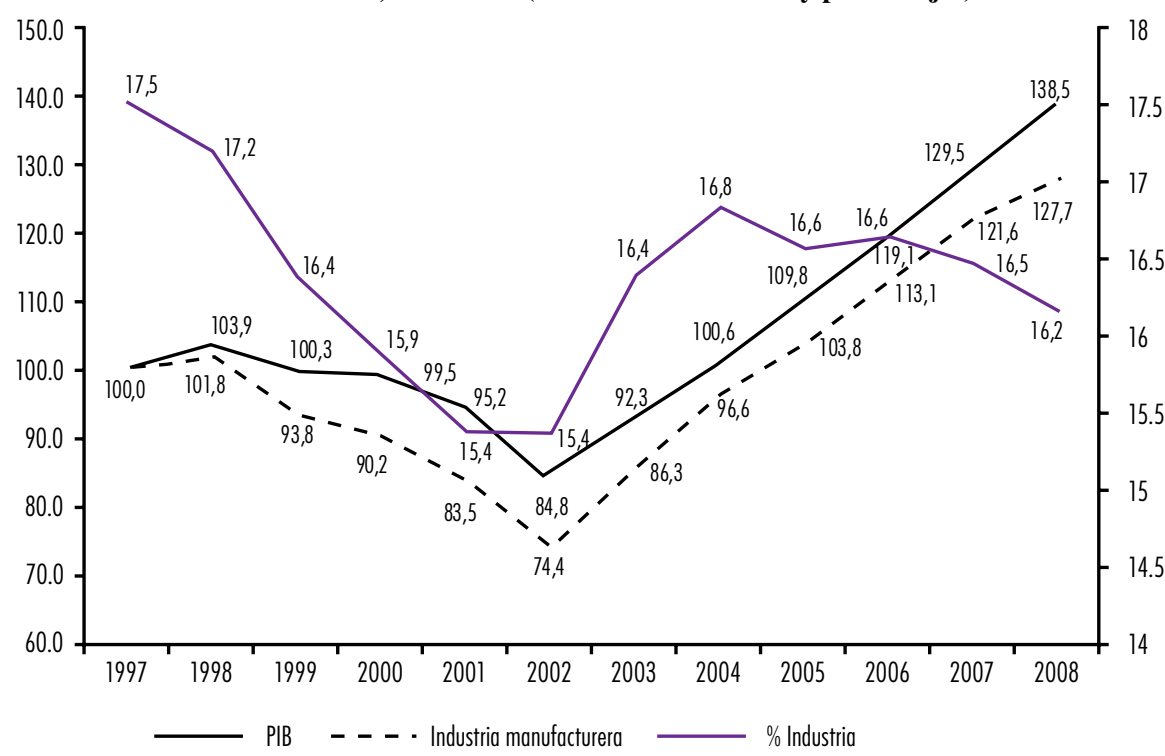

Fuente: Elaboración propia con base en información del INDEC.

Desde 2005, y en un marco de relativa desaceleración del crecimiento fabril y de la economía argentina en su conjunto, la recuperación del mercado interno pasó a contribuir sustancialmente al mantenimiento de la recuperación económica en general, e industrial en particular. En dicha expansión de la demanda interna tuvieron un papel protagónico cierta recomposición que experimentaron los salarios reales (en especial de los trabajadores registrados), la creación de empleos y, al calor de ambos procesos, una ligera progresividad distributiva.

De todas maneras, cabe resaltar que a partir de 2005 (año en el que el PIB global y el correspondiente a las actividades manufactureras alcanzaron a superar los respectivos registros correspondientes a 1998), el ritmo de crecimiento de la actividad fabril se ubicó por debajo del agregado (con la consiguiente reducción en el aporte relativo del sector), siendo la construcción (entre los rubros productores de bienes) y el trans- 
porte, las telecomunicaciones, el comercio y la intermediación financiera (entre los servicios), los ámbitos de mayor dinamismo durante el último cuatrienio. Es más, en dicha etapa, por su aportación al incremento del PIB total, la industria fue superada por el transporte, las telecomunicaciones y las actividades comerciales.

En la reactivación fabril durante la posconvertibilidad y la desaceleración de los últimos años se reconoce el afianzamiento del perfil productivo sectorial que se fue consolidando durante la década de 1990 (con sus antecedentes desde 1976). En otras palabras, la vigencia de un "dólar alto" contribuyó a profundizar gran parte de los rasgos de una estructura de especialización de escaso dinamismo a escala mundial (agroindustrias y commodities), con limitados efectos locales en términos de empleo y encadenamientos virtuosos hacia crecientes estadios en materia de productividad e incorporación de progreso técnico. Se trata, en su mayoría, de manufacturas que se caracterizan por estructuras de oferta oligopólica y en las que los salarios tienen un papel asociado a su condición de costo empresarial más que de factor dinamizador de la demanda interna.

La información que aporta el cuadro 1 resulta suficientemente ilustrativa. Apenas seis sectores de actividad dieron cuenta en 2008 de más de las dos terceras partes de la producción, casi todos ellos con participaciones crecientes respecto del periodo 1993-2001. La industrialización de recursos naturales (esencialmente agropecuarios -muy por debajo de sus potencialidades en términos de generación de valor agregado local-, aunque también derivados de los hidrocarburos), los productos químicos, la siderurgia, la producción de aluminio primario y el sector automotor se han consolidado como las actividades centrales del sector industrial argentino a favor, en la mayoría de los casos, de crecientes exportaciones, con muy bajos salarios a escala internacional y en condiciones externas favorables (sólo morigeradas a partir de la reciente crisis internacional). El único hecho auspicioso lo brinda la inclusión de la industria de maquinaria y equipo (5.3\% de la producción fabril en el último año, poco más de un punto porcentual por encima del promedio 1993-2001), fundamentalmente maquinaria agrícola y algunos otros rubros vinculados a las demandas de equipamiento de las ramas que lideran el desempeño sectorial ${ }^{6}$.

6 De todos modos, cabe apuntar que en la posconvertibilidad el sector local fabricante de maquinarias y equipos operó con significativos déficit de balanza comercial (véase el apartado 4), lo que constituye un indicador por demás elocuente de la dependencia tecnológica argentina y la vigencia de una matriz productiva que se sigue caracterizando por su carácter trunco (en el sentido de Fajnzylber, 1983). 
Cuadro 1

Estructura de la producción industrial argentina según sector manufacturero, promedio 1993-2001 y 2008 (\%)

\begin{tabular}{|c|c|c|c|c|}
\hline & \multicolumn{2}{|c|}{$1993-2001$} & \multicolumn{2}{|c|}{2008} \\
\hline & $\%$ & Acumulado & $\%$ & Acumulado \\
\hline Alimentos y bebidas & 30.5 & 30.5 & 31.1 & 31.1 \\
\hline Sustancias y productos químicos & 11.5 & 42.0 & 11.9 & 43.0 \\
\hline Vehículos automotores, remolques y semirremolques & 7.3 & 49.3 & 8.4 & 51.4 \\
\hline Máquinas y equipos & 4.2 & 53.5 & 5.3 & 56.7 \\
\hline Metales comunes & 4.5 & 58.0 & 5.2 & 61.9 \\
\hline Fabricación de coque y refinación de petróleo & 6.3 & 64.3 & 4.9 & 66.8 \\
\hline Productos de caucho y plástico & 4.1 & 68.4 & 4.4 & 71.2 \\
\hline Edición e impresión & 3.6 & 72.0 & 3.9 & 75.1 \\
\hline Papel y derivados & 3.0 & 75.1 & 3.5 & 78.6 \\
\hline Cuero y derivados & 2.6 & 77.7 & 2.8 & 81.4 \\
\hline Industria metalmecánica (excepto máquinas y equipos) & 3.4 & 81.1 & 2.8 & 84.2 \\
\hline Productos minerales no metálicos & 2.6 & 83.7 & 2.7 & 86.9 \\
\hline Productos textiles & 3.9 & 87.6 & 2.4 & 89.3 \\
\hline Equipos de radio, TV y comunicaciones & 1.4 & 89.0 & 2.4 & 91.7 \\
\hline Confección de prendas de vestir & 2.9 & 91.9 & 1.9 & 93.6 \\
\hline Madera y productos de madera y corcho & 2.0 & 93.9 & 1.9 & 95.5 \\
\hline Muebles y colchones e industrias ncp ${ }^{*}$ & 2.6 & 95.5 & 1.7 & 97.2 \\
\hline Máquinas y aparatos eléctricos & 1.7 & 97.2 & 1.2 & 98.4 \\
\hline Productos de tabaco & 0.7 & 97.9 & 0.6 & 99.0 \\
\hline Instrumentos médicos y de precisión & 0.4 & 98.3 & 0.5 & 99.5 \\
\hline Equipo de transporte & 0.5 & 99.8 & 0.4 & 99.9 \\
\hline Máquinas de oficina, contabilidad e informática & 0.2 & 100.0 & 0.1 & 100.0 \\
\hline Total industria & 100.0 & & 100.0 & \\
\hline
\end{tabular}

*ncp: no clasificadas en otra parte.

Fuente: Elaboración propia con base en datos de la Dirección Nacional de Cuentas Nacionales del Ministerio de Economía y Finanzas Públicas.

Una visión complementaria y enriquecedora remite a la identificación y la consideración de los rubros de actividad que impulsaron la reactivación fabril en la posconvertibilidad o, en otros términos, aquellas ramas que realizaron una mayor contribución al incremento agregado del PIB industrial. En ese sentido, el primer fenómeno a resaltar en torno al patrón sectorial de crecimiento surge de la evidencia de que apenas 10 actividades industriales dieron cuenta de casi $80 \%$ del incremento registrado en el PIB manufacturero en el periodo 2002-2008 (cuadro 2). Al tiempo que en el polo opuesto, seis actividades no alcanzaron a representar $6 \%$ del crecimiento del PIB fabril durante el periodo (entre las que se encuentran algunas relevantes en términos de diversificación, eslabonamientos y aportaciones al progreso técnico como electrónica industrial, maquinaria eléctrica, otros equipos de transporte -salvo el automotriz-, máquinas de oficina e informática). 
Cuadro 2

Principales ramas de actividad según su contribución al crecimiento 2002-2008 del PIB industrial de Argentina a precios constantes de 1993 (\%)

\begin{tabular}{|l|c|c|}
\hline & $\%$ & Acumulado \\
\hline Alimentos y bebidas & 19.7 & 19.7 \\
\hline Sustancias y productos químicos & 10.4 & 30.1 \\
\hline Vehiculos automotores & 10.0 & 40.1 \\
\hline Maquinaria y equipo & 9.0 & 49.1 \\
\hline Ediciones e impresiones & 6.5 & 55.6 \\
\hline Caucho y plástico & 4.9 & 60.5 \\
\hline Industrias metalmecánicas (exc. maquinaria y equipo) & 4.8 & 65.3 \\
\hline Equipos de radio, IV y comunicaciones & 4.7 & 70.0 \\
\hline Metales comunes & 4.7 & 74.7 \\
\hline Minerales no metálicos & 4.6 & 79.3 \\
\hline
\end{tabular}

Fuente: Elaboración propia con base en datos de la Dirección Nacional de Cuentas Nacionales del Ministerio de Economía y Finanzas Públicas.

Un segundo tema remite a las consideraciones precedentes relacionadas con el perfil sectorial que, remontándose a la década de 1990, ha tendido a consolidarse en la nueva fase expansiva industrial. Con la salvedad de la fabricación de maquinaria y equipo (donde, como se señaló, queda incluida la producción de maquinaria agrícola y otras destinadas a los propios "núcleos de especialización" local, como la siderurgia), han sido las agroindustrias, la automotriz, el enclave ensamblador de electrónica de consumo en la provincia de Tierra del Fuego y las productoras de commodities e insumos intermedios de uso difundido (siderurgia, aluminio primario, química básica, cemento) las que han realizado una mayor contribución al crecimiento industrial.

De lo analizado se desprende que en la posconvertibilidad se experimentó en la Argentina un proceso de reindustrialización acotado cuantitativa y cualitativamente, que se asoció a la expansión, a ritmos muy disímiles, de casi todas las actividades que integran el entramado manufacturero, con crecientes niveles de inserción en los mercados internacionales. Se trata de un fenómeno que, con sus limitaciones, merece ser resaltado a la luz de la aguda y sumamente regresiva crisis de desindustrialización verificada entre 1976 y 2001. Sin embargo, no puede soslayarse el hecho de que teniendo como sustentos básicos al "dólar alto" y la relativamente barata fuerza de trabajo (dado que casi no hubo políticas activas de fomento a las actividades fabriles), no se verificó un cambio estructural en la industria doméstica, es decir, no se avanzó en la redefinición del perfil de especialización productiva resultante de largos años de políticas neoliberales? ${ }^{7}$.

7 La lógica del "piloto automático", tan cara al neoliberalismo, pareciera haber seguido vigente; esto es, la idea de que la instrumentación de una "adecuada" política macroeconómica es la 


\section{Generación de empleo, distribución del ingreso y rentabilidad extraordinaria de las grandes empresas industriales}

En contraposición con las casi tres décadas de persistente expulsión neta de mano de obra en el sector industrial ${ }^{8}$, en la posconvertibilidad, particularmente a partir de 2003, se asistió a una franca recuperación del empleo, consistente con la propia reactivación fabril. Así, entre 2001 y 2008 la ocupación fabril se incrementó 27.4\%, porcentaje que se eleva a 40.3 si se toma como referencia el año 2002.

En relación con la dinámica laboral, la reciente publicación de los resultados provisorios del Censo Nacional Económico 2004-20059 permite constatar que la ocupación industrial en 2003 (poco más de 950000 trabajadores) supone una expulsión de más de 55000 personas respecto de una década atrás. Este fenómeno se reproduce por tercer censo consecutivo y remite a una expulsión de casi 375000 trabajadores en relación con los ocupados en la última fase del proceso sustitutivo (Censo Nacional Económico de 1974). En otros términos, al cabo de tres décadas la industria manufacturera expulsó a casi el 30\% de la dotación de mano de obra ocupada en el sector y se constituyó en uno de los sectores que más aportó a la problemática de la desocupación y la precarización laboral ${ }^{10}$.

De allí la significación que asume la recuperación del empleo industrial en la posconvertibilidad. De todas maneras, aunque tal fenómeno sea relevante, no conllevó un cambio significativo en cuanto a uno de los tantos legados de la hegemonía neoliberal: la importante presencia de trabajadores no registrados o "en negro" o precarios. La información disponible hasta el año $2007^{11}$ permite comprobar que esa creciente demanda de mano de obra por parte del sector industrial no alteró mayormente las propias condiciones de inserción en el mercado por parte de los trabajadores. En efecto, en 2007, 69.5\% de los asalariados fabriles eran registrados, porcentaje que en 2001 se ubicaba en 67.9; mientras que a mediados de la

condición para resolver los problemas económicos heredados y que casi no se requieren políticas activas si "la macro funciona bien" y "los precios son los correctos".

8 En 1974, las tasas de desocupación y subocupación se ubicaron en $2.4 \%$ y 3.8\%, respectivamente, mientras que en 2001 fueron de $18.3 \%$ y 16.3\%, respectivamente. Véase http://www. indec.gov.ar/ (consultado el 27 de octubre de 2009).

9 Disponible en http://www.indec.gov.ar/economico2005/resultados/Datos/3.c2_\%20industria. xls (consultado el 26 de octubre de 2009).

10 Una visión de largo plazo del mercado de trabajo en Argentina puede encontrarse en Arceo et al. (2008) y Beccaria, Groisman y Maurizio (2008).

11 Véase http://www.mecon.gov.ar/secpro/dir_cn/ingreso/cuadro6.xls (consultado el 26 de octubre de 2009). 
década precedente (1995), 72.3\% de la fuerza de trabajo ocupada en la industria correspondía a asalariados con acceso a la economía formal y la seguridad social. Esto sugiere que los empleos creados en la posconvertibilidad son (ligeramente) mayoritarios "en blanco", pero no implica la presencia de un proceso de transformación de los empleos "en negro" hacia su formalización, ni de un claro predominio de nuevos puestos de trabajo registrados. Al respecto, entre 2001 y 2007 la tasa de crecimiento del empleo "en negro" (23.7\%) en la industria no discrepa significativamente -como para emerger como un quiebre trascendente respecto a uno de lo tantos legados del neoliberalismo extremo de los noventa- de la correspondiente a los trabajadores formalizados (33.5\%). Cabe acotar que en 2007 el salario medio de estos últimos era 3.4 veces superior al de los asalariados industriales no registrados, y que las remuneraciones medias de los obreros "en negro" se encontraron por debajo de los valores que definen la línea de pobreza, con la consecuente aparición de una problemática adicional sobre el deteriorado mercado laboral argentino: los "trabajadores pobres por ingresos".

Más allá de este último comentario (importante en términos de la identificación de continuidades y rupturas en la posconvertibilidad vis-à-vis al modelo de los noventa), la señalada recuperación del empleo industrial debe ser interpretada junto con otras variables que remiten, en última instancia, a la relación capital/ trabajo en el interior de la industria argentina. En ese sentido, la información proporcionada en el cuadro 3 permite extraer algunas importantes inferencias:

- luego de experimentar una contracción sumamente pronunciada entre 1998 y 2002, que derivó en una elevada subutilización de la capacidad instalada, la producción generada en el ámbito manufacturero local se expandió muy fuertemente y de manera sostenida: entre el último año mencionado y 2008 acumuló un incremento de $85.2 \%$ (67.2\% respecto de 2001 );

- a raíz de los señalados patrones de desenvolvimiento de la producción y la ocupación, en la posconvertibilidad se asistió a un considerable incremento de la productividad de la mano de obra: entre 2002 y 2008 este coeficiente se expandió un 32\% (31.3\% en relación con 2001); y

- a partir de la evolución de la productividad (alza sostenida desde 2003) y los costos salariales $^{12}$, tuvo lugar un aumento extraordinario en el margen bruto de

12 Los costos salariales surgen de deflactar el salario nominal en la industria por los precios mayoristas del sector. Este coeficiente cayó en forma pronunciada en el bienio 2002-2003, y luego ingresó en una fase de cierta recuperación. 
explotación hasta 2003 (73.8\%), para luego morigerarse (igualmente en 2008 se ubicó un 20.9\% por encima de sus elevados registros de 2001). Ello denota que los empresarios del sector se apropiaron de una considerable proporción del excedente generado en el ámbito manufacturero ${ }^{13}$.

Cuadro 3

Industria argentina. Evolución de la producción, ocupación, productividad laboral y relación productividad-costo salarial, 2001-2007 (en índice base 2001=100)

\begin{tabular}{|c|c|c|c|c|}
\hline & Producción & Obreros ocupados & Productividad & $\begin{array}{c}\text { Productividad/ } \\
\text { costo salarial }\end{array}$ \\
\hline 2001 & 100.0 & 100.0 & 100.0 & 100.0 \\
\hline 2002 & 90.3 & 90.8 & 99.5 & 155.3 \\
\hline 2003 & 106.1 & 95.6 & 110.9 & 173.8 \\
\hline 2004 & 121.0 & 104.9 & 115.3 & 152.6 \\
\hline 2005 & 132.0 & 111.9 & 117.9 & 139.9 \\
\hline 2006 & 144.9 & 117.9 & 122.9 & 126.3 \\
\hline 2007 & 157.9 & 123.9 & 127.3 & 118.7 \\
\hline 2008 & 167.2 & 127.4 & 131.3 & 120.9 \\
\hline
\end{tabular}

* El costo salarial surge de deflactar el salario nominal por el IPIM (Índice de precios internos al por mayor sectorial).

Fuente: Elaboración propia con base en información del INDEC.

En suma, en la posconvertibilidad la industria fue uno de los principales sectores de la actividad económica en lo correspondiente a la generación de puestos de trabajo; pero no debería soslayarse que su desempeño se asentó una vez más sobre una considerable transferencia de ingresos (particularmente en 2002-2003) desde los trabajadores hacia los empresarios. La dinámica fabril reciente, asociada a la vigencia de bajos niveles salariales y a una elevada tasa de explotación de los obreros en actividad, no parece haber revertido algunos rasgos del desenvolvimiento sectorial verificado en la etapa 1976-2001 de predominio del ajuste estructural y la valorización financiera, con su correlato en la desindustrialización y la reestructuración regresiva del entramado manufacturero.

Asimismo, cabe destacar que la profunda modificación en la estructura de precios y rentabilidades relativas de la economía local verificada a partir del abandono de la

13 Cabe señalar que la apropiación de excedente por los capitalistas industriales en los años recientes queda subestimada a partir del proceso de manipulación de gran parte de las variables que conforman el sistema estadístico nacional por el gobierno de Kirchner y el de su sucesora. Las diversas evidencias disponibles indican que los precios minoristas (en especial) y los mayoristas han crecido muy por encima de lo que se desprende de los datos publicados por el Instituto Nacional de Estadísticas y Censo, en particular a partir del año 2007 (Bevacqua y Salvatore, 2009). 
convertibilidad hizo viable un cambio significativo en ciertos aspectos relevantes de la dinámica de acumulación y reproducción ampliada del capital de las firmas que se desenvuelven en el ámbito industrial, básicamente aquellas que ejercen liderazgos oligopólicos. A diferencia de la década de 1990, cuando una parte importante del excedente captado por el empresariado fabril (aun por los segmentos de mayores dimensiones) terminó canalizándose hacia otros sectores económicos más favorecidos que la industria por el comportamiento de sus precios (por ejemplo, los servicios públicos privatizados y diversas actividades financieras), los reordenamientos en la posconvertibilidad de los precios industriales vis-à-vis los de muchos sectores "ganadores" del decenio pasado permitieron que los incrementos en las ganancias brutas de las empresas se tradujeran en un alza notable de sus beneficios netos. En otras palabras, en la posconvertibilidad, el mayor excedente internalizado por los capitalistas por efecto de la depreciación de los costos salariales y la creciente productividad tendieron a mantenerse "dentro" de la esfera fabril y, en ese marco, a concentrarse en torno de los actores predominantes en términos estructurales.

Como una forma de aproximarse a lo señalado, en la gráfica 2 se presenta la evolución de la tasa media de ganancia neta sobre facturación de las empresas líderes que cotizan en la Bolsa de Valores, diferenciando a las industriales del resto. Los resultados son terminantes. En la década de 1990, las firmas manufactureras registraron desempeños muy pobres (en varios años operaron con abultados quebrantos contables), al tiempo que las no industriales (muchas de ellas prestadoras de servicios públicos privatizados) revelaron las más altas tasas de rentabilidad. En contraposición, en la posconvertibilidad los mayores márgenes de beneficio sobre ventas corresponden a las grandes firmas industriales.

En cuanto a este último tema cabe incorporar algunas digresiones. El derrumbe del esquema de caja de conversión y la "salida devaluatoria" conllevaron una profunda caída de la actividad económica e industrial domésticas. Sin embargo, en el ámbito de las grandes compañías fabriles ello no se vio reflejado en los balances corporativos. De ahí que no resulte sorprendente que en el crítico año 2002 la rentabilidad media sobre ventas de las líderes fabriles (1.3\%) resulte ser la más alta desde 1995.

Consolidado el reordenamiento local de los precios relativos, en un contexto de sostenida recuperación del mercado interno, con una considerable baja en los costos salariales y precios internacionales en alza para los principales rubros de exportación, a partir de 2003 queda en evidencia la internalización de márgenes de utilidad sobre ventas que se ubicaron muy por encima de los mejores registros de la década de 1990. 
Gráfica 2

Evolución de tasas de rentabilidad sobre ventas de las empresas

que cotizan en la Bolsa de Valores, según sector de actividad, 1995-1er. sem. 2009 (\%)

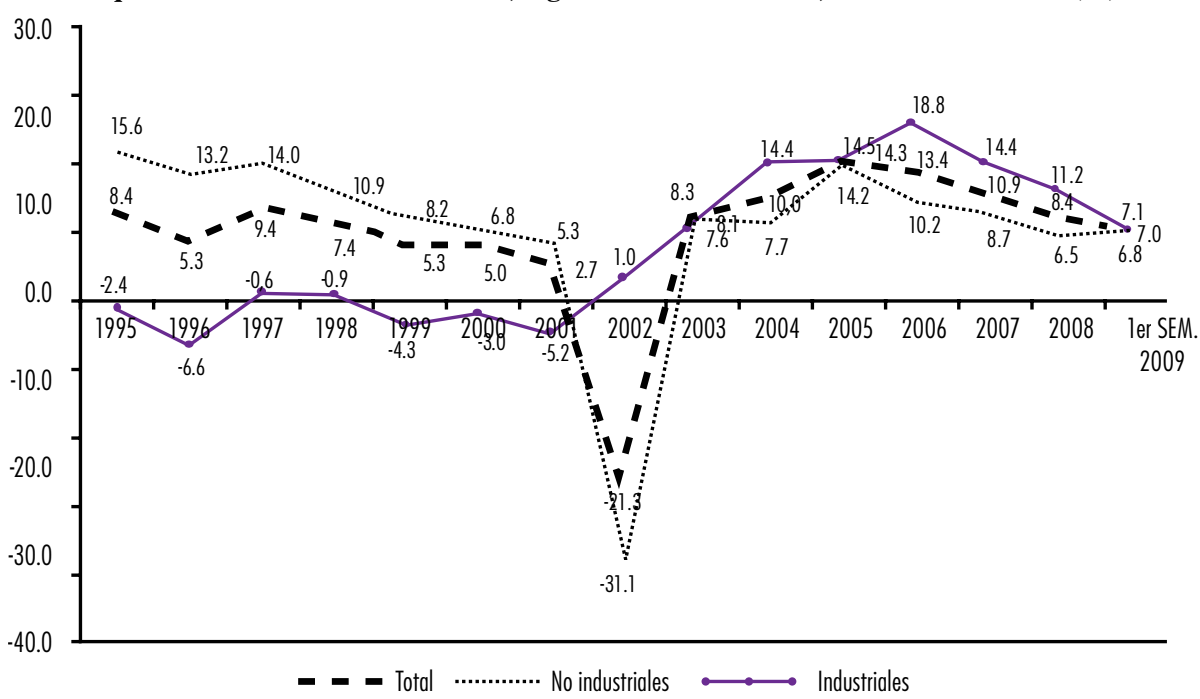

Fuente: Elaboración propia con base en información de Economática.

La reconfiguración de la estructura de precios relativos a favor de las actividades productivas y fabriles, en particular las exportadoras, la recuperación de la demanda doméstica y la reducción de los costos salariales permitieron, en conjunto, que las empresas líderes del sector pasaran a operar con tasas de rentabilidad por demás significativas. Incluso en el convulsionado 2008, cuando se conjugó un prolongado lock-out de las patronales del sector agropecuario que afectó al conjunto de la economía y la crisis económica y financiera internacional, la rentabilidad de las grandes firmas industriales fue superior al promedio (apenas en el primer semestre de 2009 tendieron a igualarse los márgenes respectivos).

Así, si bien en los años recientes la industria desempeñó un papel protagónico en términos de creación de empleo y, como resultado de ello, tuvo una nada despreciable participación en la caída de la tasa de desocupación, no puede soslayarse que en una proporción considerable fue resultado de la incorporación de mano de obra con un costo netamente inferior al promedio (asalariados no registrados) y cuyo costo de expulsión es prácticamente nulo ante una eventual reversión del ciclo económicofabril. Todo esto fue posible por la concurrencia de distintos elementos, entre los que sobresalen: $a$ ) la vigencia de un plexo normativo heredado de los noventa que aún induce y convalida la precarización laboral; $b$ ) la existencia de un "ejército industrial de 
reserva" de cierta envergadura con evidentes efectos disciplinadores sobre los obreros ocupados; y c) el "déficit de representatividad" de muchos sindicatos asociado tanto a cuestiones de índole "interna" como a la fragmentación del universo laboral.

Los análisis que anteceden también sugieren la insuficiencia estructural de la dinámica manufacturera desde el abandono de la convertibilidad. Ello se encuentra estrechamente relacionado con la reducción significativa que experimentaron los salarios obreros, contemporánea a la implosión del régimen de conversión fija (que se suma a las numerosas caídas que se habían acumulado desde mediados de la década de 1970), con un nuevo salto de nivel en cuanto a la explotación de los trabajadores y la calidad de parte importante del empleo generado en los años subsiguientes. A su vez, esto impulsó una fenomenal recomposición de las ganancias empresariales, en particular las del segmento de empresas líderes en los rubros fabriles preponderantes en el nivel estructural y con una elevada propensión exportadora ${ }^{14}$. La considerable apropiación de excedente, fundamentalmente por parte de los grandes capitalistas, sumada a los deprimidos niveles salariales, llevan a sostener que aún queda por recorrer un camino nada despreciable con vistas a lograr la recuperación de los salarios en el sector manufacturero, sin que esto implique una limitante a la competitividad de la industria argentina. Ello queda demostrado al analizar la evolución y el perfil del comercio exterior de manufacturas.

\section{Patrón de especialización externa y restricciones: los flujos comerciales}

\section{de bienes industriales}

Una de las dimensiones analíticas en las que mejor quedan plasmadas continuidades y rupturas de trascendencia entre el "modelo de los noventa" y la posconvertibilidad es la que se vincula con el desempeño de la balanza comercial de manufacturas. A la

14 Y en conjunción con otros factores, también posibilitó un fuerte incremento de la concentración económica en el ámbito manufacturero a favor de las grandes compañías. Entre tales factores, destaca: a) la importante y creciente inserción exportadora de la mayoría de los oligopolios líderes; $b$ ) la integración de los mismos a unidades económicas complejas que cuentan con un amplio abanico de opciones en materia productiva, tecnológica, comercial y financiera; c) las variadas posibilidades con que cuentan estas grandes corporaciones para captar excedentes de manera diferencial a partir del poder de mercado que detentan en diversos ámbitos manufactureros críticos para el funcionamiento del conjunto de la economía nacional (como aquellos vinculados con la elaboración de bienes intermedios de uso difundido); $d$ ) los sesgos manifiestos en el nivel normativo-institucional en lo referido al control sobre la relación entre grandes empresas y PYMES; y e) la considerable centralización de capitales que se desencadenó a partir de la profunda crisis que marcó el fin del régimen de convertibilidad (Azpiazu y Schorr, 2008). 
vez, también en dicho campo cada vez son más evidentes serias limitaciones e insuficiencias en materia de políticas públicas, particularmente en el campo de las orientadas hacia la industria o, en otros términos, que la principal, si no casi excluyente "política" se limite a mantener un elevado tipo de cambio real y costos salariales relativamente bajos.

En efecto, la vigencia de un dólar alto se constituyó en un incentivo decisivo para las exportaciones fabriles desde la implosión del régimen de convertibilidad (alta capacidad ociosa, brusca y significativa caída de los salarios e incremento de costos domésticos por debajo de la tasa de devaluación). Y, como tal, en un componente fundamental del crecimiento de la producción industrial. Asimismo, cabía esperar que ello se conjugara con una importante sustitución de importaciones por producción local (a favor del margen de protección resultante del más elevado tipo

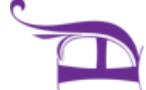
de cambio real).

A juicio de muchos, esa nueva relación cambiaria y salarial constituiría un aliciente necesario y suficiente para garantizar una expansión de las actividades fabriles, e incluso para avanzar hacia un apropiado patrón de especialización industrial y de inserción internacional. Extremando el razonamiento, no se necesitarían políticas activas ni mucho menos una estrategia integral de desarrollo manufacturero: la reindustrialización se vería garantizada con esos nuevos escenarios macroeconómicos ${ }^{15}$. En ese sentido, vale revisar el comportamiento reciente del comercio exterior de manufacturas, contrastarlo con la década de 1990 y extraer ciertas inferencias que refutan varios de aquellos argumentos.

Como queda reflejado en la gráfica 3, durante la vigencia de la convertibilidad la industria local registró abultados déficit comerciales que alcanzaron su punto extremo en 1998 (más de US \$11 200 millones) para, a partir de allí, y como derivación de la creciente recesión doméstica, morigerarse por efecto de la sostenida caída de las importaciones. Ello fue resultado de la convergencia temporal del retraso cambiario (con sus previsibles consecuencias sobre las importaciones y las exportaciones) y la pronunciada apertura de la economía. De allí la profundización del proceso de desindustrialización y reestructuración regresiva del tejido fabril expresado, entre otras dimensiones, en una acelerada reprimarización de la producción y las exportaciones sectoriales, y la desintegración y desarticulación del entramado fabril no ajena a la irrupción masiva de bienes importados abaratados (incluso a precios de dumping), sustitutivos de la producción local.

15 Véase Frenkel y Rapetti (2004). 
Gráfica 3

Argentina: exportaciones, importaciones y saldo comercial del total de manufacturas, 1993-2008 (millones de dólares)

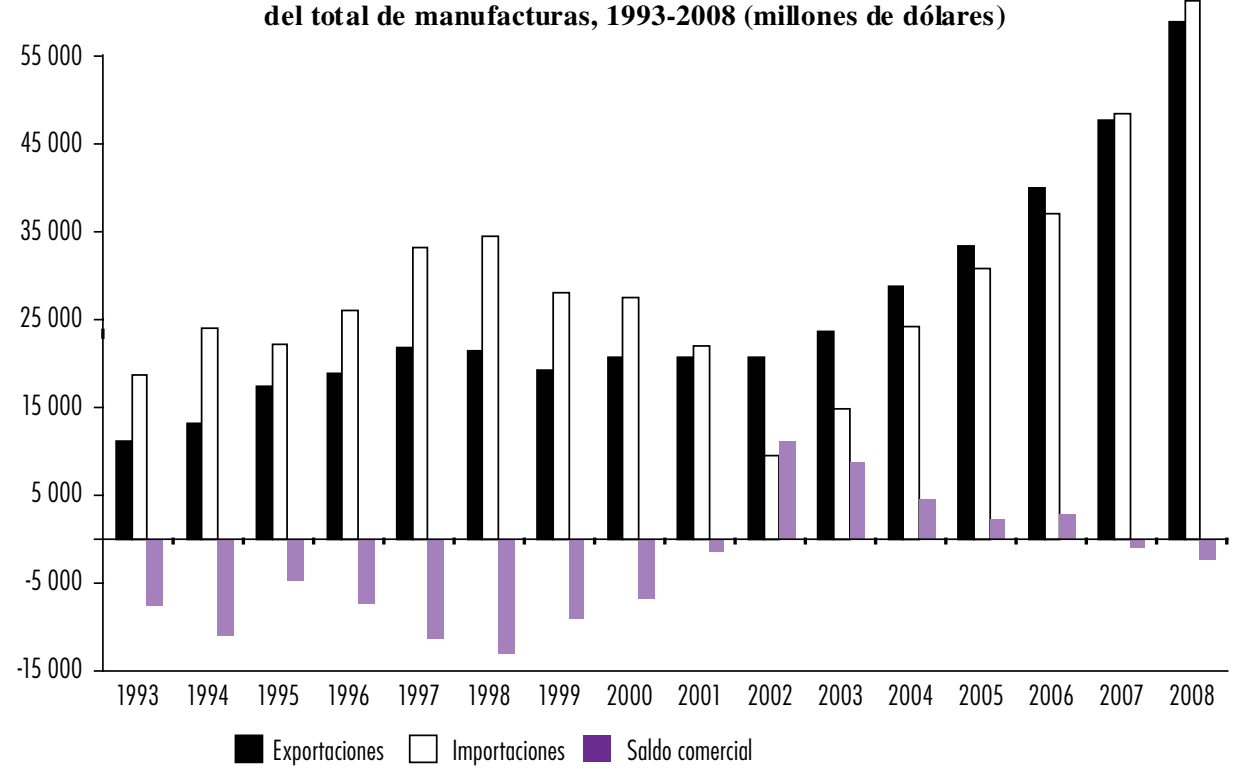

Fuente: Elaboración propia con base en datos del INDEC.

A partir de 2002, consistente con los efectos de la devaluación, se asistió a un cambio relevante ya que, después de muchos años, la industria volvió a registrar superávit en su balanza comercial. Sin embargo, a pesar de la vigencia de un dólar alto y un mercado internacional en franca expansión hasta mediados de 2008, tal balance comercial positivo tendió a disminuir hasta tornarse crecientemente negativo en el bienio 2007-2008 (alrededor de US \$700 millones y US $\$ 2000$ millones, respectivamente). Así, entre 2002 y 2008 mientras las exportaciones manufactureras crecieron a una tasa anual acumulativa de $18.1 \%$, las importaciones de bienes industriales lo hicieron a un promedio anual de $38.6 \%$, expresión de que los encarecidos requerimientos de importaciones (mayoritariamente bienes intermedios, combustibles y, en menor grado, bienes de capital ${ }^{16}$ no tuvieron un contemporáneo proceso sustitutivo de significación.

16 Las evidencias disponibles permiten concluir que en la posconvertibilidad alrededor de $60 \%$ de las importaciones correspondió a bienes intermedios y combustibles, al tiempo que la incidencia de los bienes de capital se ubicó en torno al 22-24\%. Por su parte, los bienes de consumo mostraron una participación creciente hasta ubicarse cerca del 18\% en 2008. Al respecto, véase http://www.cepal.org.ar/argentina/noticias/paginas/9/9839/Cuadro14.xls (consultado el 24 de octubre de 2009). 
$\mathrm{Al}$ respecto, la gráfica 4 permite comprobar que el coeficiente exportador agregado de la actividad (medido por la relación entre las exportaciones y la producción) se incrementó significativamente en 2002, para luego estabilizarse en torno a 26-29\%. Asimismo, luego de experimentar una fuerte contracción en el primer año de la posconvertibilidad a raíz de la profundidad de la crisis económico-fabril, la relación entre las importaciones y el consumo aparente (un indicador proxy del peso de las compras externas en la demanda doméstica) se incrementó sostenida e ininterrumpidamente: de representar 12\% en 2002 pasó a más de 30\% en 2008 (muy por encima de los registros correspondientes al boom importador del decenio anterior).

Gráfica 4

Industria manufacturera argentina. Relación entre las exportaciones y la producción, y las importaciones y el consumo aparente, 1993-2008 (\%)

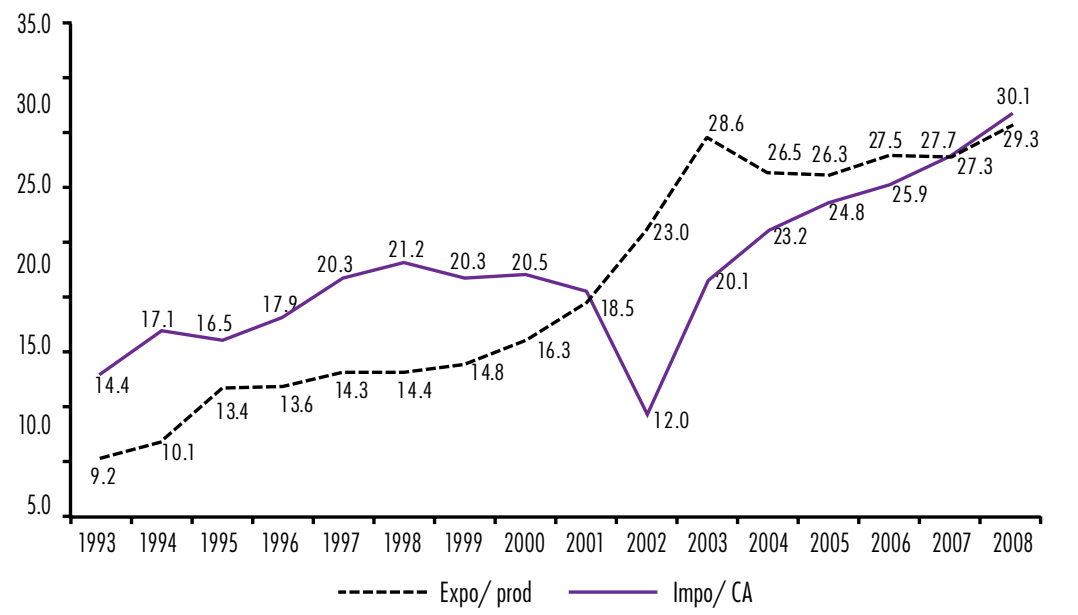

Fuente: Elaboración propia con base en datos del INDEC.

Por supuesto, todo ello no estuvo disociado de la casi ausencia de una política industrial que trascienda el dólar alto y, más aún, de una estrategia nacional de desarrollo ${ }^{17}$.

$17 \mathrm{Al}$ respecto, poco es lo que se avanzó en los últimos años: las políticas desplegadas que podrían haber generado o inducido positivamente, en forma directa o indirecta, un armónico, acelerado y sustentable proceso de desarrollo industrial en su sentido más amplio, fueron en general escasas, parciales, descoordinadas y desarticuladas. Ejemplos como los ofrecidos por la Ley de promoción del software (núm 25 922), el Decreto 774/05 por el que se creó el régimen de incentivo a la competitividad de autopartes locales, la promoción del desarrollo y la producción de biotecnología (Ley 26 770), las disposiciones del Decreto núm 1 234/07 por el que se extendió el régimen ensamblador de Tierra del Fuego hasta 2023 (vencía en 2013) y diversas líneas de financiamiento oficial a tasas bonificadas resultaron insuficientes, más allá de los problemas que se manifiestaron en su implementación efectiva y su respectiva capacidad inductora. A ello 
Cuadro 4

Estructura de las exportaciones industriales de la Argentina según sector manufacturero, promedio 1993-2001 y 2007-2008 (\%)

\begin{tabular}{|l|c|c|c|c|c|c|}
\hline & \multicolumn{2}{|c|}{$1993-2001$} & \multicolumn{2}{|c|}{2007} & \multicolumn{2}{c|}{2008} \\
\hline & $\%$ & Acumulado & $\%$ & Acumulado & $\%$ & Acumulado \\
\hline Alimentos y bebidas & 43.9 & 43.9 & 43.4 & 43.4 & 44.4 & 44.4 \\
\hline Vehículos automotores, remolques y semirremolques & 12.2 & 56.0 & 13.6 & 57.1 & 13.4 & 57.8 \\
\hline Fabricación de coque y refinación de petróleo & 5.9 & 67.9 & 10.2 & 67.3 & 11.4 & 69.2 \\
\hline Sustancias y productos químicos & 10.0 & 71.9 & 10.1 & 77.4 & 8.7 & 77.9 \\
\hline Metales comunes & 6.5 & 78.4 & 7.4 & 84.8 & 7.5 & 85.4 \\
\hline Máquinas y equipos & 3.2 & 87.6 & 2.9 & 87.7 & 3.0 & 88.4 \\
\hline Cuero y derivados & 5.7 & 87.3 & 2.7 & 90.4 & 1.9 & 90.3 \\
\hline Productos de caucho y plástico & 1.6 & 88.8 & 1.8 & 92.2 & 1.7 & 92.0 \\
\hline Equipo de transporte & 0.9 & 91.2 & 1.0 & 94.5 & 1.7 & 93.8 \\
\hline Papel y derivados & 1.5 & 90.3 & 1.3 & 93.5 & 1.1 & 94.8 \\
\hline Industria metalmecánica (excepto máq. y equip.) & 0.9 & 93.7 & 0.8 & 96.3 & 0.9 & 95.7 \\
\hline Productos textiles & 1.6 & 92.8 & 0.9 & 95.4 & 0.8 & 96.6 \\
\hline Máquinas y aparatos eléctricos & 1.2 & 95.0 & 0.8 & 97.1 & 0.8 & 97.4 \\
\hline Madera y productos de madera y corcho & 0.4 & 95.4 & 0.7 & 97.8 & 0.5 & 97.9 \\
\hline Instrumentos médicos y de precisión & 0.6 & 96.7 & 0.5 & 98.7 & 0.5 & 98.4 \\
\hline Productos minerales no metálicos & 0.7 & 96.0 & 0.5 & 98.2 & 0.5 & 98.8 \\
\hline Muebles y colchones e industrias ncp & 1.0 & 97.7 & 0.3 & 99.1 & 0.3 & 99.2 \\
\hline Confección de prendas de vestir & 0.8 & 98.5 & 0.3 & 99.4 & 0.3 & 99.4 \\
\hline Equipos de radio, TV y comunicaciones & 0.4 & 98.8 & 0.3 & 99.7 & 0.2 & 99.7 \\
\hline Edición e impresión & 0.7 & 99.6 & 0.2 & 99.9 & 0.2 & 99.9 \\
\hline Máquinas de oficina, contabilidad e informática & 0.3 & 99.9 & 0.1 & 100.0 & 0.1 & 99.9 \\
\hline Productos de tabaco & 0.1 & 100.0 & 0.0 & 100.0 & 0.0 & 100.0 \\
\hline Total industria & 100.0 & & 100.0 & & 100.0 & \\
\hline
\end{tabular}

*ncp: no clasificadas en otra parte.

Fuente: Elaboración propia con base en información del INDEC.

Y remite, por lo menos, a tres consideraciones. Primero, al escaso dinamismo relativo de las exportaciones industriales argentinas a escala mundial. Segundo, a los límites estructurales a la sustitución de importaciones asociados, por un lado, al propio redimensionamiento regresivo del entramado manufacturero local durante las últimas décadas y, por otro, a la fragilidad del empresariado nacional. Tercero, ante la inexistencia de una redefinición del grado de apertura de la economía, la estructura arancelaria y el perfil exportador, así como de una política activa de reconstrucción de encadenamientos

cabe agregar el mantenimiento, con ligeros retoques, del régimen de privilegio para el sector automotor (particularmente en el ámbito del Mercosur, para beneplácito de las transnacionales que controlan la actividad) y la aplicación, en el marco de la crisis internacional, de cupos y licencias a la importación de algunos productos. 
productivos, más temprano que tarde podrían existir presiones por el lado de las divisas (para pagar las importaciones demandadas por la industria), sobre todo si se consolidan las actuales tendencias negativas del escenario internacional.

La primera de aquellas consideraciones invita a reflexionar en torno a las características de la oferta exportadora de la industria local desagregada según los principales rubros productivos (cuadro 4). Desde esta perspectiva se comprueba que en la posconvertibilidad no se vio alterado considerablemente el perfil exportador heredado de la década de 1990. En el bienio 2007-2008 sólo cinco sectores fabriles dieron cuenta de $85 \%$ de las ventas externas totales, frente a una participación algo superior a 78\% en el periodo 1993-2001: industria alimenticia, sector automotor, refinación de petróleo, elaboración de productos y sustancias químicas, y manufactura de metales comunes (siderurgia y aluminio primario).

En su gran mayoría, se trata de actividades caracterizadas por: estructuras de oferta fuertemente concentrada alrededor de un número muy reducido de grandes compañías y conglomerados empresariales (sobre todo de capital extranjero); escasas articulaciones internas en el plano productivo; relativamente poco demandantes de mano de obra; en las que los salarios bajos (en pesos y, más aún, en moneda dura) constituyen un dato; un comportamiento muy dependiente de los ciclos del mercado mundial en materia de precios y demanda (en estos rubros el país es "tomador de precios"); y una tendencia secular a perder participación relativa en el comercio mundial o que la misma depende de las estrategias de un núcleo acotado de empresas transnacionales.

De allí surgen ciertas consideraciones insoslayables en cuanto a la relación entre el perfil industrial, su inserción a escala mundial y el desarrollo del país. En primer lugar, que el patrón de especialización productivo-exportador que se ha venido con-

solidando en la posconvertibilidad difícilmente permita que la Argentina ingrese en un sendero de desarrollo con crecientes niveles de inclusión económico-social. En segundo lugar, que la vigencia del dólar alto como eje ordenador y prácticamente excluyente de la política industrial es condición insuficiente para una modificación positiva en la inserción nacional en los flujos mundiales del intercambio comercial manufacturero.

Ello también se ve corroborado a partir del análisis del saldo comercial de los diferentes sectores industriales. Al respecto, los datos aportados por el cuadro 5 indican que en el bienio 2007-2008, en un escenario global de déficit comercial, la mayoría de las actividades manufactureras registró considerables desbalances en sus transacciones de bienes con el exterior, mientras que apenas cinco operaron con superávit (la industria alimenticia y, en mucha menor medida, la refinación de petróleo, la metálica 
básica, la producción de cuero y sus derivados, y marginalmente la industria maderera). Es más, vale subrayar que salvo la industria alimenticia, los pocos sectores que registraron superávit comercial, lo vieron decrecer entre 2007 y 2008, al tiempo que en todos los deficitarios se incrementaron los desequilibrios.

Desde esta perspectiva, todo parece indicar que en la posconvertibilidad tendió a afianzarse la "dualidad estructural" del sector manufacturero argentino, gestada al calor de las políticas desindustrializadoras aplicadas entre 1976 y 2001. Un pequeño grupo de sectores productivos ligados al procesamiento de recursos básicos presentó una balanza comercial positiva, mientras que los restantes fueron deficitarios, sobre todo a medida que se avanza hacia manufacturas más complejas, más intensivas en la utilización de conocimiento científico-tecnológico, más demandantes de mano de obra con elevada calificación, con mayores potencialidades para impulsar con su crecimiento a otros sectores y difundir el progreso tecnológico al tejido económico y social, y que por lo general han venido conformando los senderos de mayor dinamis-

Cuadro 5

Saldo comercial de los distintos sectores industriales de la Argentina 2007-2008 (millones de dólares)

\begin{tabular}{|l|c|c|}
\hline \multicolumn{1}{|c|}{ Sector industrial } & 2007 & 2008 \\
\hline Alimentos y bebidas & 17107.2 & 21689.4 \\
\hline Fabricación de coque y refinación de petróleo & 2349.0 & 1.441 .6 \\
\hline Metales comunes & 721.2 & 666.0 \\
\hline Cuero y derivados & 689.2 & 449.9 \\
\hline Madera y productos de madera y corcho & 87.1 & 51.3 \\
\hline Productos de tabaco & -7.8 & -12.2 \\
\hline Edición e impresión & -56.1 & -81.1 \\
\hline Confección de prendas de vestir & -77.2 & -188.2 \\
\hline Productos minerales no metálicos & -263.7 & -339.8 \\
\hline Papel y derivados & -363.6 & -492.6 \\
\hline Muebles y colchones e industrias ncp & -682.4 \\
\hline Productos textiles & -509.4 & -641.9 \\
\hline Industria metalmecánica (excepto máq. y equip.) & -520.2 & -1061.6 \\
\hline Productos de caucho y plástico & -704.5 & -849.0 \\
\hline Instrumentos médicos y de precisión & -710.2 & -947.5 \\
\hline Equipo de transporte & -798.6 & -1017.1 \\
\hline Máquinas de oficina, contabilidad e informática & -941.1 & -1519.8 \\
\hline Total industria & -1329.3 & -2032.1 \\
\hline Máquinas y aparatos eléctricos & -719.2 & -2068.5 \\
\hline Vehículos automotores, remolques y semirremolques & -1663.4 & -2930.8 \\
\hline Equipos de radio, TV y comunicaciones & -1701.3 & -3288.0 \\
\hline Sustancias y productos químicos & -3132.9 & -4814.0 \\
\hline Máquinas y equipos & -4246.2 & -5395.8 \\
\hline
\end{tabular}

*ncp: no clasificadas en otra parte.

Fuente: Elaboración propia con base en información del INDEC. 
mo en el comercio mundial de manufacturas ${ }^{18}$. De allí que el rubro más deficitario en el bienio 2007-2008 haya sido el de maquinaria y equipos (acumuló un desequilibrio comercial superior a US $\$ 10000$ millones).

Respecto de estas cuestiones, vale la pena incorporar dos breves comentarios. El primero se vincula al hecho de que dos de las actividades que conforman el núcleo central exportador de la industria argentina son fuertemente deficitarias en sus operaciones comerciales con el resto del mundo. Se trata de las industrias automotriz y química. En el primer caso, a pesar de contar con un régimen especial de promoción y protección a la actividad que fue puesto en marcha en los noventa y reafirmado en fecha reciente (que en lo sustantivo apunta a lograr un "intercambio compensado" con Brasil), en el bienio 2007-2008 acumuló un déficit comercial superior a US \$4 600 millones (donde el subsector de autopartes dio cuenta de alrededor de $80 \%$ del desequilibrio agregado). Asimismo, en el segundo caso el déficit de comercio correspondiente a 2007-2008 (superior a US \$9 000 millones) fue explicado fundamentalmente por las fuertes importaciones de sustancias químicas básicas y de abonos, plaguicidas y otros químicos de uso agropecuario (en conjunto estos rubros explicaron más de las tres cuartas partes de ese desequilibrio sectorial).

El segundo comentario remite a una cuestión insoslayable en términos económicos y políticos: en una industria caracterizada por esa "dualidad estructural" en materia de inserción internacional, los pocos sectores y actores que generan divisas asumen un papel central en el desenvolvimiento fabril (y en la economía en su conjunto). De allí que detenten un decisivo poder de veto o de coacción sobre la orientación de las políticas públicas.

$\mathrm{Al}$ respecto, cabe reflexionar en el comportamiento de las grandes empresas industriales en su relación con el resto del sector y de la economía nacional. En el cuadro 6 se puede apreciar la evolución del saldo comercial de esa cúpula empresarial (las 100 compañías de mayores montos anuales de facturación), el de la industria y el del conjunto de la economía en el periodo 2001-2007. Se puede comprobar que en la posconvertibilidad, la élite de los empresarios fabriles registró abultados superávit comerciales, mientras que el resto de la industria operó con desequilibrios muy acentuados y crecientes. Basta contrastar los respectivos saldos en el último año de la serie en estudio: mientras las líderes tuvieron un saldo superior a US \$15.8 miles de millones, el resto del sector registró un déficit que se aproximó

18 Un estudio de las tendencias del comercio internacional en las últimas décadas se encuentra en Amsden (2004) y Arceo (2005). 
a US \$17 miles de millones.

Tal heterogeneidad estructural refleja que las firmas que conforman la élite secto-

\section{Cuadro 6}

Argentina. Evolución del saldo comercial de la cúpula empresarial*, el total industrial y el conjunto de la economía, 2001-2007 (millones de dólares)

\begin{tabular}{|c|c|c|c|c|c|}
\hline & $\begin{array}{c}\text { Cúpula } \\
\text { industrial }\end{array}$ & $\begin{array}{c}\text { Total } \\
\text { industria }\end{array}$ & $\begin{array}{c}\text { Total } \\
\text { economía }\end{array}$ & $\begin{array}{c}\text { Resto de } \\
\text { la industria }\end{array}$ & $\begin{array}{c}\text { Resto de } \\
\text { la economía }\end{array}$ \\
\hline & $A$ & $B$ & $C$ & $D=B \cdot A$ & $E=C \cdot A$ \\
\hline 2001 & 7050.6 & -1151.6 & 6223.1 & -8202.2 & -827.5 \\
\hline 2002 & 9676.7 & 9659.4 & 16661.1 & -17.3 & 6984.4 \\
\hline 2003 & 12841.1 & 7568.2 & 16088.0 & -5272.9 & 3246.9 \\
\hline 2004 & 12343.7 & 4030.6 & 12130.5 & -8313.1 & -213.2 \\
\hline 2005 & 12059.7 & 2145.7 & 11699.9 & -9914.0 & -359.8 \\
\hline 2006 & 13423.0 & 2582.3 & 12392.5 & -10840.7 & -1030.5 \\
\hline 2007 & 15810.5 & -719.2 & 11072.1 & -16529.7 & -4738.4 \\
\hline
\end{tabular}

* Se trata de las 100 empresas industriales de mayor facturación anual.

Fuente: Elaboración propia con base en información del Área de Economía

y Tecnología de la FLACSO y el INDEC.

rial, las "ganadoras" en la posconvertibilidad, se encuentran mayoritariamente insertas en ramas ligadas al procesamiento de recursos básicos (agroindustria, hidrocarburos, acero y aluminio y sus derivados, y algunos productos químicos) y en el ámbito automotor. Dicho perfil estructural y de especialización contrasta marcadamente con el de los restantes segmentos empresariales, que en su mayoría presentan una manifiesta debilidad asociada a las propias características de la desindustrialización iniciada a mediados de la década de 1970, desarrollan sus actividades en rubros mucho más expuestos a la competencia de productos importados (a pesar del nivel de protección brindado por el "dólar alto"), presentan serias dificultades estructurales para sustituir insumos y bienes de capital importados por sus similares de origen doméstico ${ }^{19}$, y deben hacer frente a variados, complejos y adversos "factores de contexto interno" (institucionales, normativos, financieros, etcétera).

El incremento que experimentó en los últimos años el comercio internacional de las firmas líderes de la industria argentina lleva a dos conclusiones relevantes. La primera: este núcleo acotado de grandes empresas (y sus propietarios) se consolidó como sólida plataforma productiva orientada preferentemente hacia los mercados ex-

19 Entre 2002 y 2007, el coeficiente de importaciones de la cúpula (importaciones en relación con ventas totales) pasó de $10.3 \%$ a $17.7 \%$, respectivamente, al tiempo que el del conjunto de la industria (importaciones respecto a valor bruto de producción) hizo lo propio pero desde $10.5 \%$ a $28.1 \%$, respectivamente. 
ternos a partir de bajos costos salariales a escala mundial, explotación de las ventajas comparativas asociadas a la dotación de recursos naturales y el privilegiado entorno normativo del que gozaron las grandes terminales automotrices y, al menos hasta 2007 , un escenario internacional muy favorable. La segunda, estrechamente vinculada, remite al papel decisivo que le correspondió al desenvolvimiento de las exportaciones de las compañías de la cúpula en la aceleración del proceso de concentración económica experimentado desde el abandono del régimen convertible ${ }^{20}$.

En síntesis, en la posconvertibilidad se consolidó un perfil de comercio exterior industrial que refleja el agudo proceso de reestructuración regresiva iniciado con la última dictadura militar. Ello denota la fragilidad del sector en términos internacionales (con la salvedad de unos pocos espacios de acumulación caracterizados por un bajo "grado de industrialización" y controlados por grandes compañías y holdings empresariales con una significativa y creciente capacidad de coacción a partir de su posicionamiento estructural). Y refuerza lo señalado en el sentido de que en los años recientes no se manifestó un proceso de cambio estructural en el sector industrial. Es indudable que tal situación difícilmente podrá revertirse con la simple vigencia de un "dólar alto", es decir, sin un conjunto articulado de políticas activas de fomento industrial que, inscritas en una determinada estrategia nacional de desarrollo, persigan, entre otras cuestiones relevantes, un profundo replanteamiento de las formas de inserción de la Argentina en el comercio mundial de manufacturas -en la actualidad, muy afincadas en la dotación dada de factores, es decir, en las ventajas comparativas del país básicamente, abundantes materias primas y mano de obra barata.

\section{Reflexiones finales}

La crisis final de la convertibilidad y la devaluación monetaria de 2002 condujeron a un punto de quiebre histórico en la abrumadora hegemonía del ajuste estructural y la valorización financiera en la Argentina.

La profundidad de la crisis económica y fabril en 2002 no puede ser ignorada cuando se intenta analizar la consiguiente reactivación de los últimos años, sobre todo si se considera que tanto en el plano agregado como en el industrial demandó un trienio de crecimiento elevado, sostenido e ininterrumpido (2003-2005), para apenas poder alcanzar los niveles de actividad de 1998.

La brusca reconfiguración de los precios relativos que se verificó a partir de la de-

20 En relación con estas cuestiones, cabe señalar que en 2001 las ventas al exterior de la élite empresarial representaron $65.2 \%$ de las exportaciones industriales y $43.9 \%$ del total exportado por la Argentina, porcentajes que se elevaron en 2007 a 67.8 y 49.3, respectivamente. 
valuación de la moneda devino en la conformación de escenarios muy favorables para aquellos rubros productivo-industriales y actores económicos que, ante el nuevo nivel del tipo de cambio real, pudieron consolidar sus fortalezas y potencialidades exportadoras en objetivo y fuente decisiva de la acumulación y reproducción ampliada de sus capitales. Aun cuando se trate de firmas tomadoras de precios a escala mundial, el alza generalizada de los precios internacionales de las principales exportaciones manufactureras así lo garantizaban. De allí que no resulte sorprendente que hasta mediados de la presente década las exportaciones hayan sido las que sustentaron gran parte de la recuperación industrial y un superior estadio de concentración económica.

Desde la perspectiva de la "oferta", los avances sustantivos en el grado de utilización de la capacidad instalada asumieron un papel fundamental como para dar respuesta a la incipiente reactivación de la demanda interna (siempre hasta mediados del decenio), y fundamentalmente a las favorables condiciones que ofrecían las exportaciones a raíz de la conjunción de un tipo de cambio "competitivo" en lo doméstico con alzas significativas en la demanda y los precios internacionales.

El más que auspicioso ritmo de crecimiento fabril se focalizó, en gran medida, y aun superada la simple recuperación de los niveles registrados en los puntos más altos de la convertibilidad, en un grupo acotado de ramas que no suponen una ruptura con el patrón de especialización legado de largos años de neoliberalismo, ni tampoco una alteración real del modelo de acumulación y la consiguiente inserción en el mismo de las actividades industriales.

En ese sentido, en la medida en que la reactivación manufacturera estuvo esencialmente vinculada a un nuevo nivel cambiario, la vigencia de salarios deprimidos, en particular para las actividades y/o actores exportadores, y la consolidación de poderes oligopólicos en un mercado interno paulatinamente recuperado, parecerían resurgir bajo nuevas formas algunas de las restricciones y/o limitaciones de la segunda fase de la industrialización sustitutiva. Claro que ahora con niveles salariales y distributivos que llevan a añorar los vigentes hace más de treinta años.

En efecto, incluso en un escenario de "dólar alto" la dinámica del comercio exterior manufacturero reveló como tendencia un riesgo cierto de réplica matizada de las fases del stop and $g o^{21}$; ello, por cuanto las evidencias analizadas remiten a la reversión del superávit comercial industrial (resultante de tasas de crecimiento muy diferenciales entre las importaciones y las exportaciones que en su momento se vieron opacadas ante la persistencia del saldo comercial "favorable"). Por otro

21 Una estilización del ciclo stop and go durante la sustitución de importaciones se halla en Braun y Joy (1981). 
lado, de modo complementario, mientras las ventas externas mantuvieron un cierto ritmo de crecimiento, la potencial dinámica sustitutiva no parecería haber contado con las condiciones necesarias y suficientes, más allá del tipo de cambio, como para no quedar entrampada en las viejas y tradicionales restricciones y limitaciones del modelo sustitutivo.

Esto remite, por ejemplo, al análisis de los sectores industriales superavitarios o deficitarios desde la perspectiva de comercio exterior. En gran medida, las exportaciones agroindustriales fueron las que permitieron compensar los desequilibrios crecientes en materia de insumos intermedios, durables de consumo y bienes de capital. Esto último, como resultado directo de largos años de desatención, principalmente por la rama elaboradora de maquinaria y equipos y otras industrias complejas, en las que la masa crítica acumulada hasta mediados de los setenta se vio sistemática y permanentemente agredida por políticas simplistas y cortoplacistas que encontraron en el abaratamiento de los costos de inversión el principal aliciente a la formación de capital (mediante la recurrente promoción a la importación de bienes de capital y rubros afines).

La profundización de un perfil de especialización fabril y de inserción internacional estructurado en torno a ventajas comparativas asociadas a los recursos naturales y de algunas industrias maduras productoras de commodities denota muchas más continuidades que rupturas respecto al legado de los noventa y, más ampliamente, al ciclo histórico iniciado en 1976.

Similares consideraciones podrían hacerse extensivas a la problemática distributiva en la industria, aunque en parte se vean menguadas al tomar como punto de referencia la brutal transferencia de recursos del trabajo al capital en el crítico año 2002. La posterior recuperación de los salarios y fundamentalmente del empleo permitió a los trabajadores reconquistar parte de sus ingresos agregados, sin que ello implicara afectación alguna a la extraordinaria apropiación del excedente por parte de los capitalistas industriales, en especial por las fracciones más concentradas.

Ello se vio reflejado en los más que considerables márgenes de rentabilidad internalizados por las grandes firmas manufactureras que, por una parte, no fueron más que la resultante esperable de la depreciación salarial y la creciente productividad, y, por otra, en una proporción no muy significativa se canalizó hacia la formación de capital ${ }^{22}$.

22 La inversión de las grandes empresas manufactureras en los años recientes ha estado directamente relacionada con la captación de cuantiosos recursos estatales procedentes del régimen de 
Así, puede concluirse señalando que desde el abandono de la convertibilidad la industria logró recuperar parte del terreno perdido entre 1976 y 2001. Pero no debe soslayarse que con independencia del "dólar alto", casi no se avanzó en la definición estratégica y la instrumentación de políticas públicas tendientes a sustentar una reindustrialización del país ligada a una considerable redefinición del perfil de especialización productiva, una diferente inserción en la división internacional del trabajo y crecientes grados de autonomía nacional asociados, entre otras cosas, a una mayor integración local de la producción y la creación de ventajas competitivas dinámicas; todo esto, de la mano con una redistribución progresiva del ingreso y la consecuente potenciación del mercado interno ${ }^{23}$.

Prueba de todo lo que no se ha hecho es que, como surge de las evidencias analizadas en este trabajo, la expansión reciente del sector manufacturero derivó, a pesar del ostensible y en muchos sentidos favorable cambio acaecido en los contextos macro y mesoeconómicos, en la consolidación de dos de los principales legados críticos del proceso desindustrializador de la etapa 1976-2001: a) una estructura fabril desarticulada y trunca, muy sesgada hacia las primeras etapas de la transformación manufacturera y con marcadas heterogeneidades estructurales y desacoples en los niveles intra e interindustriales; $\mathrm{y} b$ ) una redistribución de ingresos en detrimento de los trabajadores y a favor de las fracciones más concentradas del capital.

"promoción de inversiones" resultante de la Ley núm. 25924 y sus normas complementarias. Este esquema "promocional" se ha caracterizado por su concentración en unas pocas empresas de gran envergadura con inserción predominante en las ramas "ganadoras" en la posconvertibilidad (agroindustria, refinería, automotriz, acero y aluminio). Un análisis de las características y los impactos estructurales sobresalientes de este régimen puede encontrarse en Azpiazu y Schorr (2008).

23 En Arceo (2009) y Ortiz y Schorr (2009) se plantea una serie de lineamientos estratégicos sobre los que se podría estructurar un programa de industrialización de la Argentina en función de los criterios aludidos. 


\section{Bibliografía}

Amsden, Alice, "La sustitución de importaciones en las industrias de alta tecnología: Prebisch renace en Asia", Revista de la CEPAL, núm. 82, Santiago de Chile, abril de 2004.

Arceo, Enrique, "América Latina. Los límites de un crecimiento exportador sin cambio estructural", en Enrique Arceo y Eduardo Basualdo, Los condicionantes de la crisis en América Latina. Inserción internacional y modalidades de acumulación, Buenos Aires, CLACSO, 2009.

,"El impacto de la globalización en la periferia y las nuevas y viejas formas de dependencia en América Latina", Cuadernos del CENDES, Caracas, septiembre-diciembre de 2005.

Arceo, Nicolás, Ana Monsalvo, Martín Schorr y Andrés Wainer, Empleo y salarios en la Argentina. Una visión de largo plazo, Buenos Aires, Capital Intelectual, 2008.

Azpiazu, Daniel, "La industria argentina ante la privatización, la desregulación y la apertura asimétricas de la economía. La creciente polarización del poder económico", en Daniel Azpiazu y Hugo Nochteff, El desarrollo ausente. Restricciones al desarrollo, neoconservadurismo y elite económica en la Argentina. Ensayos de economía política, Buenos Aires, FLACSO-Tesis Norma, 1994.

Azpiazu, Daniel y Martín Schorr, Hecho en Argentina. Economía e industria, 19762007, Buenos Aires, Siglo XXI editores (en prensa).

, La industria argentina en la posconvertibilidad. ¿Nuevo régimen de acumulación ofase de reactivación?, Buenos Aires, Fundación Friederich Ebert Stiftung-Central de los Trabajadores Argentinos, 2008.

Basualdo, Eduardo, Estudios de historia económica argentina. Desde mediados del siglo XX a la actualidad, Buenos Aires, FLACSO-Siglo XXI editores, 2006.
Beccaria, Luis, Fernando Groisman y Roxana Maurizio, "Notas sobre la evolución macroeconómica y del mercado de trabajo en Argentina, 1975-2007”, en Luis Beccaria y Fernando Groisman (eds.), Argentina desigual, Los Polvorines, Bs. As., UNGS, 2008.

Bevacqua, Graciela y Nicolás Salvatore, "Argentina. La reconstrucción de la Serie de Inflación Minorista. El IPC City", Buenos Aires City, Buenos Aires, febrero de 2009, en http://www.lanacion.com.ar/anexos/informe/70/41970.pdf

Braun, Oscar y Leonard Joy, "Un modelo de estancamiento económico. Estudio de caso sobre la economía argentina", Desarrollo económico, vol. 20, núm. 80, Buenos Aires, enero-marzo de 1981.

Fajnzylber, Fernando, La industrialización trunca de América Latina, México, Nueva Imagen, 1983.

Frenkel, Roberto y Martín Rapetti, "Políticas macroeconómicas para el crecimiento y el empleo", Buenos Aires, CEDES-OIT, 2004 (mimeo).

Katz, Jorge, Cambios estructurales y evolución de la productividad laboral en la industria latinoamericana en el período 1970-1996, Santiago de Chile, CEPAL, Serie Reformas Económicas núm. 14, 1999.

Kosacoff, Bernardo (ed.), El desempeño industrial argentino más allá de la sustitución de importaciones, Buenos Aires, CEPAL, 2000.

, Estrategias empresariales en tiempos de cambio. El desempeño industrial frente a nuevas incertidumbres, Buenos Aires, CEPAL, 1998.

Ortiz, Ricardo y Martín Schorr, "Crisis internacional y alternativas de reindustrialización en la Argentina", Documentos de Investigación Social, núm. 7, IDAES-UNSAM, 2009. 